\title{
22
}

\section{Helping Students Find Their Way to Meaning: Meaning and Purpose in Education}

\author{
Michael F. Steger, Maeve B. O’Donnell, and Jessica L. Morse
}

\section{Introduction}

In some ways, youth is a time for dreaming, and growing up is a time for pruning dreams. Granted, not all dreams make a lot of sense. Longabandoned dreams of being a freelance time-traveller or heavy metal guitar hero are no great loss. Other dreams may have held the aspirations that could have blossomed into our meaning and purpose. Those bits of childhood are sad to see forfeited. As parents and educators, we play an inevitable part in the pruning of young dreams. Would we consider learning how to better guide youth in discerning which of their passions and aspirations can be nurtured to become the foundation for their meaning in life?

The role of educators in bolstering meaning may be a vital one. Meaning in life is a fundamental cornerstone of wellbeing and flourishing. Even a couple of decades ago, the empirical research needed to support such an audacious statement was just beginning to build. Now, though, the surge in research makes it impossible to ignore meaning in any endeavour directed at improving the human condition, including in the burgeoning field of positive education.

M. F. Steger $(\varangle) \cdot$ M. B. O’Donnell · J. L. Morse Colorado State University, Fort Collins, CO, USA e-mail: Michael.F.Steger@colostate.edu

M. F. Steger

North-West University, Vanderbijlpark, South Africa 
As early as the 1930s and 1940s, Viktor Frankl was arguing that the need for meaning was a fundamental human drive, perhaps the most human of all our drives (Frankl, 1963). Frankl fused the terms meaning and purpose, and despite differences we will review below, research on meaning and purpose has grown together. The first claim that meaning was a core part of wellbeing came from Carol Ryff, who included the highly goal-directed construct of purpose in her influential psychological wellbeing theory in the late 1980s (Ryff, 1989). Yet it was not until the mid-2000s that a sufficiently robust body of research began to build a strong case for the importance of meaning and purpose.

By including a dedicated chapter on meaning, this Handbook recognizes that meaning in life will only grow in importance among those interested in helping others cultivate happy, fulfilling lives. How are we so confident that meaning in life will continue to gain influence? According to the scholarly publication indexing service Web of Science, the number of papers published each year on "meaning in life" did not reach 200 until the mid2000s. Compare that to the nearly 5,000 papers published on meaning in life in 2019 alone. In fact, more research papers have been published on meaning in life in the past four years than in all the preceding years combined. This research has shown that meaning in life is a positive indicator of happiness, psychological wellbeing, better mental health, greater kindness, more frequent useof character strengths, healthier adaptation to stress, greater resilience, more frequent volunteering, more positive social interactions, higher gratitude, more robust physical health, more proactive utilization of health care resources, and, as has been shown many times over, longer life (for reviews, see O'Donnell et al., 2014; Steger, 2012b; Steger, 2019). Cutting edge research continues to explore the benefits of meaning in life around the world, among young and old, on the scale of nations and of neurons. Meaning in life is, truly, a fundamental cornerstone of wellbeing and flourishing.

The conundrum seems to be that as awareness and scientific grounding of the importance of meaning to our functioning as people grows, so too does an anxiety about the dissolution and disappearance of the grand sources of meaning that once provide steady footing for understanding who we are and what we are supposed to do in this life. Several sources document a rise in psychological distress among younger people. For example, an analysis of two large national datasets of American undergraduate students showed that depression, anxiety, non-suicidal self-injury, suicidal ideation, and suicide attempts all heightened profoundly from 2007 to 2018 (Duffy, Twenge, \& Joiner, 2019). Our stressed young people grow into a world that has seen 
the government, marriage, social clubs, service leagues, religious institutions, corporations, and athletic organizations come up wanting as guides to navigate life. Where once people could unquestioningly rely on their leaders, neighbours, parents, clubs, religious leaders, and coaches for stability and reliable advice, these institutions are frequently waning in numbers of participants, revealed as arenas for corruption, or simply challenged on the truth or goodness of their message. At the same time, there are indications that young people are more blatantly interested in meaning than previous generations, especially in their work lives (Gallup, 2016).

There is a gap, then, between what young people want and what we appear to offer them as a society. Given the high levels of distress among young people and the large body of research showing that meaning in life is related to better wellbeing and mental health, it appears worthwhile to seek more effective ways of encouraging and supporting the search for meaning among youth. More than ever, schools appear to be an important resource. Hence, this chapter aims to point towards some ways to understand the meaning in life and integrate it into positive education curricula.

\section{Research on Meaning in Life in Youth, Development, and Education}

Oft and inaccurately cited as a primarily adult endeavour, finding and making meaning in life is built into the fabric of human existence from a very young age. One need only gaze into the confused expression of an infant, endure a never-ending string of why questions from a 4-year old, or converse with a teenager just cut from the varsity basketball team to determine that meaning matters. Undoubtedly, the search for and experience of meaning in youth is commensurate with cognitive development and endurance. Our attentions, our goals, our strivings, and our interpersonal interpretations in our youth help to form the basis for our meaning-making endeavours in adulthood. Developmental research has only recently begun to answer questions about a typical path for a highly nuanced and personal journey. Although meaning in childhood is guided by curiosities, wonderings, and emerging understandings of the self in the world, adolescence is marked by identity formation, strivings, and the protective role of meaning as a buffer against the common trappings of the teenage years. 


\section{Childhood}

Globally, experiencing life as meaningful during one's youth is associated with many of the benefits that persist through adulthood. Youth and adolescents who report that their lives are meaningful report better psychological health, higher life satisfaction, and better emotional wellbeing (Brouzos, Vassilopoulos, \& Boumpoli, 2016; Burrow, O’Dell, \& Hill, 2010; Cavazos Vela, Castro, Cavazos, Cavazos, \& Gonzalez, 2015; French \& Joseph, 2009; Shochet, Dadds, Ham, \& Montague, 2006). Youth who endorse that their lives are meaningful also navigate their worlds with an increased sense of hope (Feldman \& Snyder, 2005) and are more likely to believe that they have the agency to make change in the world (Schwartz, Côté, \& Arnett, 2005). On the flip side, youth who report that their lives lack meaning are more likely to report worse mental health and difficulty with adjustments in psychological and social domains as they get older (Shek, 1992). In sum, youth whose lives are less meaningful may be adrift-having difficulties finding emotional and social footing - while those who report a life imbued with meaning are more likely to operate with hope, satisfaction, and sound mental health.

The childhood years lend themselves naturally to a focus on coherence, with an emergent understanding of how the world works and how one fits into their surroundings. Qualitative research suggests that children as young as seven years old can describe trying to make meaning from difficult experiences inconsistent with an orderly and predictable world, such as recovering from a car accident or being diagnosed with cancer (Kang, Im, Kim, Song, \& Sim, 2009; Salter \& Stallard, 2004). In fact, the majority of youth who had experienced a traumatic event in childhood described parallel processes consistent with meaning-making, such as experiencing a shift in expectations about the world and its inherent safety and taking stock of what is important to them (Park, 2010). Quantitative efforts have followed suit, and Shoshani and Russo-Netzer (2017) developed and validated a measure to assess the presence and sources of meaning in the lives of children. They found that meaning in childhood is centred around three facets: (1) creativity, which revolves around making a difference in the child's surroundings, (2) experience, which is focused on what inspires the child about the world, and (3) attitude, which reflects how the child perceives the world, including difficult events. These three facets roughly translate to the modern tripartite view of significance, purpose, and coherence, respectively (Martela \& Steger, 2016), and may set the stage for identity formation, cognitive interpretations consistent with meaning-making, and strivings in adolescence and adulthood. 


\section{Adolescence}

In adolescence and young adulthood, there appears to be a fundamental shift from primarily self-in-world focused endeavours to a clearer emphasis on purpose and striving in pursuit of one's passions. Striving may be so foundational to meaning in adolescence that adolescents seem to experience difficulty distinguishing the cognitive and motivational components of meaning. When high school and college students were randomly assigned to write about purpose, meaning, or a control topic, there were no identifiable differences between the purpose and meaning conditions, and many young people assigned to the meaning condition explicitly mentioned purpose (Ratner, Burrow, Burd, \& Hill, 2019). This sense of mission or purpose is associated with greater psychological wellbeing in young adulthood, and people report higher life satisfaction, positive affect, self-esteem, emotional processing, emotional expression, and fewer depressive symptoms if they can identify a clear mission in their lives (Chen, Kim, Koh, Frazier, \& VanderWeele, 2019). A robust body of literature suggests that meaning and purpose are also linked to achievement in adolescence. Meaning and purpose have been found to influence adolescents' aspirations and life trajectories, predict better academic performance, feelings of connectedness to school, career curiosity, and career confidence (Bailey \& Phillips, 2016; Martin Sanz, Rodrigo, Garcia, \& Pastrana, 2017; Yuen \& Yau, 2015). Finding passions during adolescence and young adulthood may provide solid ground with which youth can navigate the uncertainty of the world around them and work towards what matters to them.

It is unsurprising, then, that adolescents and young adults who report that their lives are meaningful are less likely to engage in risky health behaviour, are more likely to take steps towards proactive health care and behaviours, and are generally more resilient. Adolescents and young adults with a strong sense of purpose may be naturally drawn to envision a future they want to enact. As such, there may be an increased commitment to making healthy choices for a life worth protecting, and people may be driven by the fact that who they are and what they do matters. In addition, a life imbued with purpose may provide a stronger lens with which to interpret difficult experiences.

Early studies of meaning and resilience found a clear connection between the two (Bernard, 1991; Masten \& Reed, 2002), and more recent studies have highlighted the profound protective role of meaning in the context of difficult experiences. In a large study of youth aged 10 to 21 of whom nearly $90 \%$ had reported being victimized, a sense of purpose emerged as the most robust predictor of resilient mental health (Hamby, Taylor, Mitchell, Jones, \& 
Newlin, 2018). In essence, a strong connection to something beyond the self was extremely important in navigating difficult life experiences (GonzalezMendez, Ramírez-Santana, \& Hamby, 2018; Hamby et al., 2018). In a corroborating line of work, after the terrorist attacks of September 11th in the U.S., students with high levels of meaning were more likely to report posttraumatic growth, whereas those with low meaning in life experienced higher levels of posttraumatic distress (Steger, Frazier, \& Zacchanini, 2008), which suggests that operating from a foundation of meaning may have psychological benefits. Further, in a sample of Filipino high school students, those with higher grit had a decreased likelihood of depression and that relationship was explained by meaning in life, suggesting a highly influential role of meaning in reducing mental health symptomatology (Datu, King, Valdez, \& Eala, 2019). Meaning and purpose may provide an adaptive cognitive lens and behavioural goals consistent with one's mission, which proves useful when interpreting and bouncing back from some of life's most difficult experiences.

Meaning also appears to be highly influential in terms of adolescent and young adult health behaviour. Multiple studies have found that adolescents who report that their lives are highly meaningful are less likely to use substances (Aloise-Young, Hennigan, \& Leong, 2001; Brassai, Piko, \& Steger, 2011) and are more proactive with maintaining their health (FitchMartin, Steger, Fitch-Martin, Donnelly, \& Rickard, 2015). Meaning in life is associated with decreased lifetime odds of experiencing suicidal ideation and suicide attempts (Kleiman \& Beaver, 2013; Tan, Chen, Xia, \& Hu, 2018), and researchers have found that adolescents living in poverty who reported having a sense of purpose were less likely to engage in antisocial behaviours (Machell, Disabato, \& Kashdan, 2016). Navigating a life filled with meaning and the requisite behaviours associated with meaning may be a protective pathway by which adolescents and young adults operate.

\section{Education/Learning}

Multiple school-based programs have been implemented to directly or indirectly foster meaning in life for school-aged youth. Some meaningfocused curricula in schools include meaning as one tool among many positive psychological skills, such as those based on the Positive Emotion, Engagement, Relationships, Meaning, Achievement (PERMA) framework (Seligman, 2011). PERMA-based programs have taken place in wrap-around school-based efforts, such as the Geelong Grammar School in Australia (Williams, 2011), and in programmatic ways such as the Flourishing Life Program in Hong Kong (Au \& Kennedy, 2018), and the Maytiv Program 
in Israel (Shoshani \& Steinmetz, 2014). Emerging results show indirect pathways to meaning, such as an increase in enjoyment and engagement in school, increased focus and mindfulness, use of character strengths and a rise in meaningful conversations among students, although very few studies have specifically assessed meaning in life as a malleable target in and of itself (Au \& Kennedy, 2018; Shoshani \& Slone, 2017; Shoshani, Steinmetz, \& KanatMaymon, 2016; Williams, 2011). Some programs, such as the My Precious Life program in Korea (Kang, Shim, Jeon, \& Koh, 2009) and the Make Your Work Matter pilot program (Dik, Steger, Gibson, \& Peisner, 2011) directly target logotherapeutic and purpose-driven efforts to enhance meaning in life and meaning in work. Across these meaning-focused programs, the experimental groups reported higher meaning in life, a clearer sense of career direction, more insight into themselves, and better preparedness for the future (Dik et al., 2011; Kang et al., 2009). Although meaning-focused intervention efforts have been at the forefront of many positive education programs, many aspects of what enhances meaning remain elusive in the intervention literature.

\section{A Primer on Meaning in Life Theory}

Meaning in life is thought to be a necessary part of human psychological and spiritual life. Viktor Frankl, a pioneer in the study of meaning in life, observed the necessity of having a sense of meaning to survive imprisonment in World War II concentration camps. Frankl (1963) observed that his fellow Holocaust survivors were able to endure suffering and persist under the most atrocious conditions if they held onto a reason for living, whereas those who lacked a strong sense of mattering or lost their grasp of what made life worth living perished. Research supports Frankl's observations, as people who experience their lives as meaningful tend to be resilient and experience posttraumatic growth (e.g., Weathers, Aiena, Blackwell, \& Schulenberg, 2016). People who report their lives as meaningful also experience better physical and psychological health as compared to individuals who report low levels of meaning in life (e.g., Ryff, 1989; Peterson, Park, \& Seligman, 2005; Steger, Frazier, Oishi, \& Kaler, 2006).

Before delving further into meaning in life theory, it is important to distinguish between the topic considered here, meaning in life, and a related topic, the meaning of life. Beginning centuries before Frankl, philosophers, psychologists, religious personnel, and lay people pondered existential questions regarding the meaning of life. The philosophical question, "what is 
the meaning of life?," differs from psychological research focused on people's sense of meaning in life. Whereas the meaning of life question is too broad and abstract to be answered via empirical investigation, the aim of psychological research on meaning in life is to examine factors that contribute to people's experience of meaning in their lives and the consequences of experiencing meaning.

The core components of meaning in life have been investigated by psychologists for decades. From Frankl's pioneering publications until recently, numerous potential dimensions of meaning have been proposed; however, three dimensions of meaning in life appear central in recent theoretical papers (e.g., Martela \& Steger, 2016; George \& Park, 2016). These three dimensions include (1) coherence: a cognitive component determined by one's experiences, self, and world making sense; (2) purpose: a motivational component that denotes pursuing and attaining core goals; and (3) significance: an evaluative component defined by a sense of mattering (e.g., Heintzelman \& King, 2014; Martela \& Steger, 2016). The coherence and purpose components appeared in the early works of Battista and Almond (1973) and Reker and Wong $(1988,2012)$. To round out their tripartite model, Reker and Wong $(1988,2012)$ proposed an affective component, consisting of feelings of satisfaction and happiness related to attaining goals. This affective component has not received much further attention; however, the coherence and purpose facets they defined have been retained in current theoretical conceptualizations. Heintzelman and King (2014), George and Park (2013), Steger (2012a) and perhaps others mention "significance" as a third dimension; however, significance was not elaborated upon until Martela and Steger (2016) and George and Park's (2016) tripartite models of meaning.

These authors (George \& Park, 2016; Martela \& Steger, 2016) propose that the three dimensions tap into different facets of the human experience of meaning and fulfil diverse functions. Thus, here we describe each of the dimensions independently and identify their potential relevance to students' paths to meaning. Coherence refers to the sense that oneself and one's experiences in the world make sense. Humans innately seek out environments that make sense to them as such environments provide predictability and stability, requiring less adaptation and work. When reliable patterns can be detected and expected relationships between things in the world exist, humans experience an evolutionarily based sense of reward. The sense of stability and coherence that comes from things being as they should contributes to a sense of meaning (Heintzelman \& King, 2014). When something is out of place or something unexpected occurs, we experience a disruption, a sense of lacking 
coherence, which can trigger efforts to make sense of the situation. We inherently seek to resolve these discrepancies so that we can perceive of our world and ourselves as comprehensible, predictable, and stable (e.g., Heine, Proulx, \& Vohs, 2006; Heintzelman \& King, 2014). We strive to understand how we fit in the world to maximize our chances for survival, thus we seek to maintain coherence and re-establish it when it is lacking.

Coherence is a natural partner to learning. At perhaps the most basic level, coherence is both a propellant and product of learning about oneself (e.g., identity development) and the world. Children and adolescents often ask "why" questions that reflect their curiosity about the world and who they are to try to make sense of their experiences. When they experience a discrepancy or recognize a deficit in understanding, they seek information and strive to learn to re-establish a sense of coherence. Many of these discrepancies can be resolved via independent learning, exploration, and reflection; however, there may be times when guidance from external sources (e.g., parent, teacher, counsellor) may be warranted.

As an example, let's consider the case of Jane, a high school senior at the top of her class who just received rejections from the five colleges to which she applied. Prior to these rejections, she considered herself a well-rounded, strong student who expected to be admitted to her preferred college and go on to attend medical school to become a paediatrician. After receiving rejections from all of these schools, Jane's beliefs about herself (e.g., capable, smart), her world (e.g., competitive, successful student), and her ability to do what she wants in the world (e.g., become a doctor) all waiver. These rejections make Jane question her understanding of the world and how she fits into it. As she struggles to make sense of this experience, she may feel disoriented. Helping Jane reflect upon this experience, building upon her abstract thinking and perspective-taking capacities, as she strives to make sense of this experience may be crucial in supporting her self-efficacy and resilience. Additionally, providing Jane with tools to deepen and expand upon her knowledge about herself and the world may be helpful. For example, encouraging Jane to formally assess her strengths and values with a career or guidance counsellor may be beneficial to furthering her understanding of herself. Organizing informational interviews for Jane to talk with students who have experienced college rejection initially but have gone on to pursue their dream careers may also be beneficial in enhancing Jane's sense of efficacy as well as her understanding of the world and how to overcome such challenges. Developmentally, many students experience these types of junctures that inform the picture they build of who they are and how they fit in the world around them. Helping students develop reflective and abstract 
thinking so they can thoughtfully consider who they are, make sense of the world around them, and navigate challenges and discrepancies is crucial to building and maintaining the coherence dimension of meaning.

The second dimension, purpose, has been used synonymously with meaning in life (e.g., Reker \& Peacock, 1981); however, there is empirical support for purpose as a construct distinct from meaning (e.g., George \& Park, 2013). When conceptualized as a distinct component contributing to meaning in life, purpose refers to "values in action", future-oriented goals that provide a sense of direction to one's actions in life (e.g., Martela \& Steger, 2016). Purpose is a natural partner to achievement and striving. When students are motivated by a sense of purpose, they are more likely to take actions (e.g., attend classes, study, etc.) to move towards their goals. Students who experience high levels of purpose are more motivated by academic achievement (Damon, 2009), are more intrinsically motivated (Bailey \& Phillips, 2016) and perform better academically (Bailey \& Phillips, 2016; Martin Sanz et al., 2017) than their peers who report lower levels of purpose. Yet, many students experience periods of "drifting," wherein they are not engaged in purposeful goals nor do they have strong intentions to pursue purposeful activities. Youth who report higher levels of exploration are more likely to experience higher levels of commitment to purpose as they age (Burrow et al., 2010). Encouraging exploration of purpose and identity may promote coherence, growth, and engagement in valued actions that result in greater intrinsic motivation, approach orientation, and achievement (e.g., Lawford \& Ramey, 2015).

Let's return to the case of Jane. Not only did receiving college rejections challenge Jane's sense of coherence, but they also may have triggered questioning of her purpose. Prior to receiving rejections, Jane thought that her actions (e.g., obtaining good grades, volunteering at a children's hospital) would help her move towards her valued goals of attending college and then medical school to become a paediatrician. Now, she questions her place in the world and wonders if she can achieve this aim. Helping Jane engage in reflection about her purpose is critical: Why does she want to become a paediatrician? How does this purpose align with her strengths and values? Are there other careers that would fit with her strengths and values? Are there other avenues towards her goal? What steps can Jane take now to continue moving towards her valued aims? As Jane reflects on these questions, it may be helpful for her to discuss her thoughts with a counsellor or mentor. She may also benefit from help identifying and considering options that may be unfamiliar to her like taking a "gap year" to focus on learning medical skills or working with children or attending a year of community college to 
strengthen her application. Helping Jane identify options that would enable her to move towards her ultimate career goal may enable her to maintain a sense of purpose and facilitating exploration of other avenues towards valued goals may encourage greater flexibility in how she pursues her purpose.

The third dimension, significance, is defined by people's sense that their lives inherently matter, are worthwhile, and have value beyond their achievements (e.g., George \& Park, 2016). For example, cultivating close relationships with family members may contribute to one's feeling of mattering and one's sense that life is meaningful, but cultivating relationships may not necessarily be perceived of as an explicit goal or accomplishment. Evaluating one's life as mattering is positively associated with students' psychological wellbeing and health and negatively associated with anxiety, depression, and suicidality (see Flett, Khan, \& Su, 2019 for a review). Significance is a natural partner to self-worth, when we feel like our lives matter, we inherently experience a sense of worth. Further, when we feel like our lives matter, we tend to make choices to safeguard our lives and promote our wellbeing. Youth who report that their lives are meaningful also report better psychological health (Brouzos et al., 2016; French \& Joseph, 2009; Shochet et al., 2006). Additionally, a sense of mattering appears to buffer against suicidality, self-harm, and engagement in other unhealthy or risky behaviours (e.g., Aloise-Young et al., 2001; Flett et al., 2019; Kleiman \& Beaver, 2013). Thus, it appears meaning and specifically the significance component of meaning, serves an adaptive role in promoting wellbeing and resilience.

Students may experience reductions in their sense of mattering when they encounter challenges or go through transitions. Let's return to the example of Jane. Prior to receiving college rejections, Jane felt as though she mattered to many people in her life and experienced a stable sense of self-worth. Although she still feels as though her life matters and inherently has value, her sense of significance is not as strong and stable as it was. She begins to question if her life will mean anything if she cannot go to college, wondering how she can contribute to the world. As Jane's worldview and view of herself is shaken (coherence) and she questions if she can make a difference in the way she once imagined (purpose), her sense of self, her sense of value, and her sense of mattering (significance) are shaken. Jane will likely need time and support in the aftermath of this meaning-shattering experience. To support her sense of significance, it may be beneficial to remind Jane of her inherent worth and point out the ways in which her existence positively impacts the lives of those around her. 


\section{The Many Roles of Meaning in Life in Positive Education}

Coherence, purpose, and significance each create opportunities for educators to create specific activities, lessons, examples, and labs. A class session could focus on helping students take knowledge about themselves, such as character strengths or gratitude, and engage in abstract thinking to imagine a thriving future life, including the types of environments, people, and activities that would surround and support them. This would be a lesson on coherence. Similar lessons could be developed specific to purpose, which might build on existing teaching about goals and choices expanded to include a consideration of matching goals with one's values, or learning to use long-term motivations to propel short-term motivations. Finally, significance lesson plans could focus on integrating information on bullying, kindness, compassion, belongingness, and social contribution to help students see how they can matter in the larger world by helping build a more inclusive and appreciative school environment for others.

In addition to the potentially exciting lesson plans mentioned above, the three dimensions of meaning in life offer many opportunities for integration into core academic curricula. There are natural affinities of each of the three dimensions with certain disciplines:

- Math and the Sciences can be discussed in terms of coherence. One of the remarkable elements of these disciplines is the universality of their aims and models. Math is not just about one calculation working out in a particular way, it is about universal laws of quantity and relationship. Physics is not about my kicking a ball and it travelling $20 \mathrm{~m}$ and you kicking the same ball and it travelling $25 \mathrm{~m}$ and we leave it at that. Instead, physics is about universal laws of force, friction, and specific applications to legs, shoes, spin, and weather conditions during our kicking contest. In other words, mathematics and the sciences are about exploring, articulating, and testing the underlying rules of the world around us. This really is another way of trying to explain what coherence is about. Coherence also is about exploring, articulating, and testing the rules we believe are true about ourselves, the world, and life. There is ample evidence that math and science instruction and testing are more effective when contextualized in students' lives (e.g., Bottge \& Hasselbring, 1993; for a review, Perrin, 2011). Perhaps contextualizing these disciplines beyond familiar or useful scenarios and positioning them within the broader scope of how students 
encounter the world around them could yield both wellbeing and learning benefits.

- Economics and Finance classes can be discussed in terms of purpose. Both economics and finance tackle the matter of how we understand, quantify, and allocate our resources toward particular outlets. Just as individually almost all of us have a limited and finite financial budget, all of us have a limited and finite time budget in our lives. Learning to keep track of that budget helps us prioritize future goals, even when we might really be craving that second round of drinks, that second streaming entertainment service, or that second car. Learning to keep track of how we spend our time, in light of our future goals, also helps us prioritize the actions that keep us moving toward the future that will be fulfilling for ourselves and others. Economics can be viewed in not-so-dissimilar terms, with ideas about rationality, market participation, competition, and incentives mapping onto the way in which we maintain our purposes for our lives and see the factors that influence our degree of commitment toward them. Especially in light of the global financial crisis that began in 2008, economics and finance instruction seems to have sought ways to integrate ethics as a way to shape consequential decisions (e.g., Ramirez, 2017) as well as ways to present a less orthodox view of established economic "truths" (e.g., Olesen \& Madsen, 2017). Both of these efforts seem to create opportunities to open discussions about why we make choices in life and toward what ends, which is a competency that is central to living with purpose.

- History and other Social Studies can be discussed in terms of significance. Both courses lend themselves to learning tools for viewing experiences from multiple perspectives, which is a coherence-oriented skill, but both also carry within them implicit assumptions about the stories and events worth relaying, worth learning. The selection of events to be included in history lessons, as well as the way in which those events are portrayed and linked are, themselves, lessons in how we make decisions on what matters, what is of value, and what is worthwhile. The way in which commonalities and differences are chosen and portrayed in social studies courses offer similar decision points. Making these decisions explicit may help students understand that they too are engaging in selection, editing, and framing of their life experiences. Hopefully they can apply their selection and editing skills to their experiences in ways that strengthen their commitment to lives that have value, are worthwhile, and that matter. There may be a dual benefit for both wellbeing and content learning objectives, as preparing students to live in a globalized world requires 
competencies of perspective-taking, discourse, and valuing (e.g., Agbaria, 2011).

These are overly simplistic generalizations, of course, but the point here is to illustrate what it might look like to infuse a Math, Economics, History, and other lessons with meaning in life. The intent of such an infusion is primarily to help students create lives of greater meaning, but as noted, there are possibilities that periodically framing core academic content in terms of the three dimensions of meaning could assist in pedagogical goals and student learning as well. No research has been presented demonstrating this, however, so much of what has been put forth here is optimistic and speculative.

Just as there may be natural affinities among the dimensions of meaning and certain academic content areas, there is a great deal of freedom and creativity with which these connections can be made. The connections simply need to be translated and elaborated. Perhaps the most useful mindset to accomplish the aim of infusing meaning into a variety of curricula and content areas is to view meaning as a living thing; one that has highly idiosyncratic expression in individuals but otherwise relies on quite common processes. As a teacher, my portfolio of meaning might differ from my students' portfolios, but we each used the same processes to create them. Here are some examples of how meaning might be translated into messages that are compatible with a greater variety of subjects. A living, breathing meaning will focus on processes and themes rather than conclusions and "right answers". Thus, from a purely meaning-centric view, we might argue:

- Math, Chemistry, Physics, Biology, Earth Sciences: It's really about understanding hidden, fundamental truths and learning how to detect them (coherence).

- Social Studies and Languages: It's really about viewing the world and life from different perspectives (coherence), and learning to understand what people judge truly matters and why they feel it is important (significance).

- Finances, Economics, and other Numbers: It's really about working towards an important outcome, and understanding how choices and incentives help or interfere with that work (purpose).

- Writing and Literature: It's really about how people navigate their circumstances and how their choices reflect who they are and the lives they are seeking to lead (purpose).

- History and Environmental Studies: It's really about how we impact the world around us, about seeing the interconnections among events and 
people, about whose stories we choose to tell, and how those determinations change over time (significance).

- Music and the Arts: It's really about learning structures and forms, the benefits of practice, and finding a creative expression of the self (coherence) with a particular eye toward how art can and does reach out to and affect the audience (significance).

- Psychology is of course about all of these!

Hopefully these light-hearted examples contain kernels of a deeper truth. Meaning, in fact, is all around us, always being constructed, changed, applied, recycled, and renewed. It provides both a profound framework for engaging students in a more thorough consideration of content material and also numerous hooks for using core academic curricula to teach students vital competencies for cultivating a meaningful, purposeful life.

\section{Meaning as a Standalone Topic}

Meaning in life can also be taught as a specific topic on its own. The three facets of meaning (coherence, purpose, significance) lend themselves to students utilizing their own personal experience to bring these abstract concepts to life and to understand the intertwined nature of meaning. In its most basic sense, educators can start by asking what makes their students' lives meaningful. Beginning a conversation in this way may allow students time to reflect, and ultimately share, that which feels most important to them. Educators may also enlist the use of visual means, such as requesting that their students take pictures of what is meaningful in their lives-thereby capitalizing on different sensory experiences to tap into meaning and allowing students to present one to two photos to the larger group/class (Steger et al., 2013). In six to ten people "meaning workshops" delivered at our home institution, participants reported benefit of not only sharing what is meaningful to them, but in also hearing the stories shared by others in their group.

For an extended emphasis on meaning in the classroom, it may be helpful to present an age-appropriate, developmentally suitable model for students while adapting the language to terminology that students can understand (e.g., see Park's, 2010 meaning model). Students could be asked to discuss or write about an experience which did not seem to make sense to them, elucidate which expectations about themselves or the world this experience seemed to violate, and note the strategies they used to come to a resolution. For example, a middle school student may note that they have a classmate who was diagnosed with cancer, that this violated the expectation that people 
their age do not get critically ill, and their worldview shifted, such that they know that young people can get sick and that it is important to make the most of each day.

Students can also be challenged to identify and discuss their passions, their strivings, and future goals and how their current time spent does or does not reflect these goals. In the past, we have asked students to log their daily activities, to decide if these activities feel purposeful (with the acknowledgement that not every task feels that way), and to identify ways in which they may be able to schedule more purposeful activities into their calendar. Further, since purpose is a natural partner to experiential learning, school-based programming can be directed towards providing opportunities for students to participate in activities aligned with what they are passionate about (e.g., charity or community events). Students can also be prompted to reflect on both the connection they felt to the activities that they participated in, how they have come to understand themselves or the world around them in a different way, and the way(s) in which what they did mattered to other people. Although theoretical models may encourage a strict interpretation of meaning, encouraging self-reflection and providing instrumental support for experiential activities for youth can help students to engage with a personal, dynamic and ever-evolving sense of what makes life meaningful for them.

\section{Meaning as a Framework for Positive Education}

Meaning is a higher order, abstract, and integrative construct, and therefore should have utility as a framework for positive education. Many positive educational institutions offer their stakeholders models that speak to the nature or identity of the institution itself. Often these models evoke the style, values, guiding principles, or way of the institution. Linking positive education to the identity of a school is an important contribution to stakeholder investment. From a meaning perspective, this would seem to be a key step to take in that it builds coherence for the positive education curriculum. However, it is hard to escape the "grab-bag" impression that the wider field of positive psychology typically offers educators. Among the most prominent topics in positive education are mindfulness, positive emotions, character strengths, kindness, meaning and purpose, growth and optimistic mindsets, goals, and gratitude. These are all worthy components in positive education and in personal growth. But what theory points towards these specific topics? What theory helps us understand why certain topics are included and others 
are excluded? More importantly, when we look past the valuable contribution of a positive educational institution's identity, what holds these topics together and weaves them into an integrated tapestry?

Unlike many of these standalone topics, meaning is by its very nature integrative. When we develop meaning in life, we integrate our selfunderstanding, past events, future goals, and current state into one notion of who we are and why we are here. We suggest that meaning can serve a similar integrative function for positive education programs. When we say to students that we want education to be a generative part of their creation and pursuit of a meaningful life, we pave the way for talking about strengths, optimistic outlooks, belonging, generosity, learning, resilience, and understanding. Rather than risking coming off as a string of loosely related lesson plans, each topic in positive education is provided with a common mission: to help students build and pursue meaningful lives.

The three dimensions of meaning in life also offer specific categories into which common positive psychology topics readily fit:

- Coherence: Current common positive education practices include emotions (e.g., gratitude), emotion regulation, mindfulness (e.g., serenity), and character strengths (Norrish \& Seligman, 2015; Waters, 2011). Each of these can be addressed within coherence (self-understanding and selfmanagement) and there would still be room to integrate additional concepts. For example, the basics of positive relationships with others can be explained in terms of coherence. That is, as we understand ourselves through introspection and analysis of how our behaviour succeeds or fails in the world, we also work to understand that other people, too, will introspect and will judge events as successful or unsuccessful. We begin to model and forecast how we can be a part of others' successes and which kinds of people might inhibit or promote our own success. A coherence framework may elegantly link the idea that we want to understand and modulate our emotions and our attention in order to participate more effectively in the lives of other people.

- Significance. The effort of schools to create models of positive education that are grounded in the institutional identity shows the potential value in rooting what is important in what is right for us. One way to look at such efforts is that schools are working to express who they are and what is important to them in a way that mobilizes and inspires their stakeholders among parents and in the community. This process can be seen as a way to ground significance in coherence. Many of the topics included in positive education also speak to ways in which the who we are strives to matter to 
the wider world. For example, belonging, kindness, prosocial behaviour, and service offer students ways to make a difference, contribute, and ultimately see that they matter. Significance also answers the question of if "it" is worth it, whether the "it" refers to school or even life. By taking on this scary question, significance can offer a way in which concepts like growth mindset and optimistic explanatory style enable us to stay engaged despite difficulty because we know that striving for a better future is "worth it."

- Purpose: It is impossible to speak of striving without mentioning purpose. Purpose is our vision of what might be, a vision we may commit ourselves to and work towards. Striving for a purpose requires the coherence of knowing who we are and what the world needs, and it requires the ability to identify what is significant and what matters. In addition, the pursuit of purpose requires the ability to both formulate intermediary steps that give us a sense of progress and to maintain motivation in the face of obstacles, fatigue, distractions, or even simply feeling blasé about our identified purposes. Other common positive educations practices that focus on mental toughness, grit, and goals can be addressed and united within purpose. Because purpose is both about the pursuit of purpose (which is motivational and self-regulation) and about the capacity to discern an appropriate purpose, it works well with the self-knowledge base of coherence and the evaluation base of significance. We would ideally like to find purposes for ourselves that speak to our uniquely best natures and will also make a positive contribution to the world. Therefore, even within purpose there still is room for teaching about values, character strengths, positive relationships, connectedness, selflessness, and many other prosocial elements of positive education.

\section{Meaning as a Common Language Within Education}

Because meaning has such rich potential as an integrative concept, it is possible to use the idea of meaning in life as a way of helping students, educators, administrators, support staff, parents, communities, and governing bodies frame the importance of education itself. It can be integrated across curricula to provide a common language for the importance and mission of education.

In many ways, articulating the importance and proper role of education is an extremely pressing matter. Scholars argue that in response to the global financial crisis, the fundamental nature of some disciplines, such as entrepreneurship and finance, need to change in order to better prepare students to understand and address the ethical and environmental crises that 
seem endemic to the modern world (e.g., Rae, 2010). Others have argued that the entire endeavour of higher education needs to intentionally work towards the public good (e.g., Kezar, Chambers, \& Burkhardt, 2015). Such calls accompany other movements that seem diametrically opposed, such as the increasing influence of for-profit corporations in schools (e.g., RobertsMahoney, Means, \& Garrison, 2016) and amplified calls for education to refocus on preparing students for work and career (e.g., Symonds, Schwartz, $\&$ Ferguson, 2011). Unless the public good can be defined as helping create productive workers and free-spending, brand-loyal consumers for corporations, then educators are caught between multiple driving imperatives.

For schools facing budget crunches, teacher shortages, greater student needs, and escalating classroom populations, it can be appealing to partner with businesses looking to fund, and brand, part of the educational experience. And the answer "So that you can get a good job" is a simple and effective rejoinder to the perennial student moan of "why do I need to know this?" Framing education in purely extrinsic or transactional terms has its risks for student motivation, whereas helping students find intrinsic reasons to value education should help boost their motivation in school (see Niemiec \& Ryan, 2009 for a review). It may be possible to use meaning in life as a framework for why education is intrinsically important.

First, meaning in life is inherently about building and enacting a life worth living. This is a journey that research resoundingly shows has strong implications for our emotional, psychological, physical, and social wellbeing. Embedding education within the student pursuit of meaning in life offers students an invitation to personalize and take ownership over their learning.

Second, the key dimensions of meaning in life are each present within education. As meaning in life theory elaborates, there is heavy emphasis on each person gaining greater understanding of one's self and the broader world around us, and to creating internalized models of how self and world coexist and co-operate. Education, too, emphasizes the tools of understanding, and positive education in particular highlights tools for self-understanding. Education sets forth numerous goals for students, ranging from content knowledge to skill acquisition and on through graduated "levels" of immersion, mastery, and expertise within a range of topics leading to a variety of opportunities for employment and contribution. Thus, education can be seen as an inherently purposeful endeavour.

Finally, education is embedded within a whole host of conclusions and judgements about the worthwhileness, value, and significance of human achievement. Each content area, each curricular decision, each exam, example, and assignment, is an exercise in choosing what matters more and 
passing on what matters less. Making each of these choice points more transparent and elaborating on the processes by which they are made can also offer students the chance to apply similar processes to their own lives, while humanizing the educational endeavour.

\section{Meaning-Focused Educational Activities}

Meaning in life is somewhat of a paradox. It is considered to be a fundamental psychological need, yet there also is the perception that we live in a critical time of meaninglessness. Meaning has a universal shape and form, yet its expression in each of us is ornately idiosyncratic. We look to wisdom, science, or the example of others for clues about how our lives can be more meaningful, yet unless we make such answers our own they will not deliver their promises. Throughout this chapter, the question of what meaning is has received extensive attention. However much we understand about what meaning is, the more pressing question for most is how to get it. Meaning is coherence and significance and purpose, so at least in the abstract we should just get ourselves a bunch of coherence and significance and purpose, right? But in this sense, meaning is like a river. We can learn that a river is water, but that does not mean that if we need a river in our lives, we just need to get some water. Like a river, meaning in life is always moving, and while it may follow a similar path, it is always changing. Meaning in life is not about what we have, it is about how we live.

Another way to say this is that meaning in life is a process not an outcome. If the ultimate goal of positive education is to empower and equip students to build lives worth living, then our students will need a process for living meaningfully. In this section, two tools are presented that can be used as living metaphors for the process of infusing meaning ever more profoundly in one's life. Ideally, both of these tools satisfy a basic set of requirements: they can change over time, they can be used with a wide range of sophistication depending on the student, and they can integrate insights and information from students' lives on an ongoing basis. Essentially, what we need are iterative, scalable, personal activities for travelling on the pathway of a meaningful life. In our experience and practice, Life Narratives and Meaning Maps satisfy these three requirements. 


\section{Life Narratives}

There are stories that speak to us today that have their origins thousands of years in the past. Battles among gods and humans, great floods and fires, love and family, devotion and betrayal, futile quests, all of these themes are explored in our oldest stories as well as modern media. The flexibility of stories makes them ideal partners for exploring meaning (e.g., McAdams \& McLean, 2013). Like meaning, they are integrative by nature, in that they can pull in vast amounts of many types of information, and link into a common structure. Narrative stories also are in motion, they are suitable for showing how growth, success, mistakes, and setbacks can flow together to make the present interpretable.

Narrative stories can be used to help students capture the three dimensions of meaning in life in an intuitive and natural fashion. Coherence can be seen as the characters and setting, the way in which a student makes sense of their relationships and interactions, and in the themes, students discern in their life experiences. Significance can be expressed through episodes in which students grapple with difficult issues, describe how and why they worked to overcome hardship, and can culminate in an overall message that their stories are valuable and worth telling, and that their character and journey really matters. Purpose can be written by students to describe the sense of plot and momentum in their lives, building excitement and clarity over where the story is going next.

Application. The narrative story approach to building meaning can be used in multiple ways. Following our overall suggestions in this chapter, meaning could be included as a teaching point where relevant in literature and media studies classes, or it could be used as a framework for understanding the structure of stories that students read. Most importantly, students could be assigned to periodically craft their own narratives to help them draw out themes of coherence, significance, and purpose, and to integrate the other elements of positive education they are learning. For example, the common approach to character strengths of telling a story of one's self at one's best would not need to exist as a standalone assignment, the insights learned through this strengths-based storytelling exercise could be integrated into a larger tale about how students are growing into their own understanding of themselves and their capacities to benefit the world around them.

Regardless of the specific application, the best potential use of the narrative story application would be as a living document that is revisited and added to throughout a student's education. By having students work with their stories 
over time, they are able to gain continuity across their positive education and have a common platform for integrating growth and learning. And just imagine what a story each student would graduate with, demonstrating the experiences and maturation from childhood to adolescence.

\section{Meaning Maps}

Our second suggestion is to use maps as a tool for building meaning across a student's education. Maps have highly adaptable characteristics that meld well with meaning in life. Maps show sites of importance and interest, they show routes from one site to another, they show the sites and features that are along the way, they characterize the general landscape both near and far, and they help us locate ourselves in the world around us. Further, maps can help students play with the ideas of coherence, significance, and purpose. Perhaps an example is helpful.

It is difficult to think of an actual map that everyone might know, so for convenience, we will use a map of Manhattan, New York, U.S. Its commercial, advertising, and media influence has made Manhattan the "New York City" most people think of. Its famous landmarks, its simple long shape, and its clear boundaries also make it an easy example to use. Imagine planning a visit to Manhattan. You might hope to see Central Park, the Empire State Building, and the Statue of Liberty, so you highlight their positions on your map and notice how they line up across the length of Manhattan. Seeing where these sites are in relation to each other creates coherence around their relationship. The fact that you have chosen these locations as your desired sightseeing destinations expresses their significance to you. As you plan your journey from one landmark to the next, that creates a sense of purpose. Filling in the map with other sights to see is a process of learning about the world around you, it might create a desire to see other destinations, and you may shape your future plans accordingly.

Application. The way we use maps as a tool for meaning is to have people create some symbols representing themselves in the centre of their workspace, whether that's paper, a screen, or whiteboard. Usually, this symbol is a variation on a stick figure, but we do not judge. Then we ask people to start putting important people, ideas, habits, experiences, places, really almost anything that is important to them around their symbol. They can represent these "destinations" in any way they care to. They can include sad destinations or happy destinations, there are really almost no rules. The only rules we suggest are to try to use proximity as an indicator of the importance of the relationship. Usually people put family members in a cluster quite near 
their symbols. Although people can add to or revise their maps at any time, when they slow down or feel that it is "good enough for now," we ask them to use their maps to help us understand who they are, what their world is like, what are the important destinations on their map, what the relationships are like among the many destinations, and where they think they are going to go next. In this way, students' meaning maps give them a way to visually represent as well as talk about their lives in a highly personal way, and a way in which they are the undisputed experts.

\section{Conclusion}

Whether students use narratives or maps, or whether their core curriculum is infused with the themes and language of meaning, their wellbeing and thriving is likely to rest substantially on their ability to find their way to meaning in life. A vast amount of research clarifies the important and foundational role meaning plays in wellbeing, which can lead to the temptation to simply "add it to the list" of practically infinite services educators feel they need to provide. Our hope with this chapter is not to simply put more jobs on the shoulders of educators. It is our view that the very nature of meaning in life makes it possible to use as an organizing framework for positive education, and so prioritizing meaning makes teaching the other aspects of positive education easier.

As the world seemingly stumbles to its knees on a regular basis, the competencies for building meaning in life can help students make sense of the ever-changing world, discern and support the importance of their own lives in the bigger picture, and formulate and pursue worthy aspirations to the benefit of their selves and their communities. Those seem like admirable dreams to nurture.

\section{References}

Agbaria, A. K. (2011). The social studies education discourse community on globalization: Exploring the agenda of preparing citizens for the global age. Journal of Studies in International Education, 15(1), 57-74.

Aloise, P. A., Hennigan, K. M., \& Leong, C. W. (2001). Possible selves and negative health behaviors during early adolescence. the Journal of Early Adolescence, 21(2), 158-181. 
Au, W. C. C., \& Kennedy, K. J. (2018). A Positive Education Program to Promote Wellbeing in Schools: A Case Study from a Hong Kong School. Higher Education Studies, 8(4), 9-22.

Bailey, T. H., \& Phillips, L. J. (2016). The influence of motivation and adaptation on students' subjective well-being, meaning in life and academic performance. Higher Education Research \& Development, 35(2), 201-216.

Battista, J., \& Almond, R. (1973). The development of meaning in life. Psychiatry, $36(4), 409-427$.

Bernard, B. (1991). Fostering resiliency in kids: Protective factors in the family, school, and community. Retrieved from https://files.eric.ed.gov/fulltext/ED335781.pdf.

Bottge, B. A., \& Hasselbring, T. S. (1993). A comparison of two approaches for teaching complex, authentic mathematics problems to adolescents in remedial math classes. Exceptional Children, 59(6), 556-566.

Brassai, L., Piko, B. F., \& Steger, M. F. (2011). Meaning in life: Is it a protective factor for adolescents' psychological health? International Journal of Behavioral Medicine, 18(1), 44-51.

Brouzos, A., Vassilopoulos, S. P., \& Boumpouli, C. (2016). Adolescents' subjective and psychological well-being: The role of meaning in life. Hellenic Journal of Psychology, 13(3), 153-169.

Burrow, A. L., O’Dell, A. C., \& Hill, P. L. (2010). Profiles of a developmental asset: Youth purpose as a context for hope and well-being. Journal of Youth and Adolescence, 39(11), 1265-1273.

Cavazos Vela, J., Castro, V., Cavazos, L., Cavazos, M., \& Gonzalez, S. L. (2015). Understanding Latina/o students' meaning in life, spirituality, and subjective happiness. Journal of Hispanic Higher Education, 14(2), 171-184.

Chen, Y., Kim, E. S., Koh, H. K., Frazier, A. L., \& VanderWeele, T. J. (2019). Sense of mission and subsequent health and well-being among young adults: An outcome-wide analysis. American Journal of Epidemiology, 188(4), 664-673.

Damon, W. (2009). The path to purpose: How young people find their calling in life. New York: Free Press Paperbacks.

Datu, J. A. D., King, R. B., Valdez, J. P. M., \& Eala, M. S. M. (2019). Grit is associated with lower depression via meaning in life among Filipino high school students. Youth \& Society, 51(6), 865-876.

Dik, B. J., Steger, M. F., Gibson, A., \& Peisner, W. (2011). Make your work matter: Development and pilot evaluation of a purpose-centered career education intervention. New Directions for Youth Development, 132, 59-74.

Duffy, M. E., Twenge, J. M., \& Joiner, T. E. (2019). Trends in mood and anxiety symptoms and suicide-related outcomes among US undergraduates, 2007-2018: Evidence from two national surveys. Journal of Adolescent Health, 65(5), 590598.

Feldman, D. B., \& Snyder, C. R. (2005). Hope and the meaningful life: Theoretical and empirical associations between goal-directed thinking and life meaning. Journal of Social and Clinical Psychology, 24(3), 401-421. 
Flett, G., Khan, A., \& Su, C. (2019). Mattering and psychological well-being in college and university students: Review and recommendations for campus-based initiatives. International Journal of Mental Health and Addiction, 17(3), 667-680.

Frankl, V. E. (1963). Man's search for meaning: An introduction to logotherapy. New York: Washington Square Press.

French, S., \& Joseph, S. (2009). Religiosity and its association with happiness, purpose in life, and self-actualization. Mental Health, Religion, \& Culture, 2, $117-120$.

Gallup (2016). How millennials want to work and live. Retrieved from https://www. gallup.com/workplace/238073/millennials-work-live.aspx.

George, L. S., \& Park, C. L. (2013). Are meaning and purpose distinct? An examination of correlates and predictors. The Journal of Positive Psychology, 8(5), 365-375.

George, L. S., \& Park, C. L. (2016). Meaning in life as comprehension, purpose, and mattering: Toward integration and new research questions. Review of General Psychology, 20(3), 205-220.

Gonzalez-Mendez, R., Ramírez-Santana, G., \& Hamby, S. (2018). Analyzing Spanish adolescents through the lens of the Resilience Portfolio Model. Journal of interpersonal violence, 0886260518790600.

Hamby, S., Taylor, E., Mitchell, K., Jones, L., \& Newlin, C. (2018). Polyvictimization, trauma, and resilience: Exploring strengths that promote thriving after adversity. Journal of Trauma \& Dissociation, 1-20.

Heine, S. J., Proulx, T., \& Vohs, K. D. (2006). The meaning maintenance model: On the coherence of social motivations. Personality and Social Psychology Review, 10(2), 88-110.

Heintzelman, S. J., \& King, L. A. (2014). (The feeling of) meaning-as-information. Personality and Social Psychology Review, 18(2), 153-167.

Kang, K., Im, J., Kim, H., Kim, S., Song, M., \& Sim, S. (2009). The effect of logotherapy on the suffering, finding meaning, and spiritual well-being of adolescents with terminal cancer. Journal of Korean Academy of Child Health Nursing, 15(2), 136-144.

Kang, K. A., Shim, J. S., Jeon, D. G., \& Koh, M. S. (2009). The effects of logotherapy on meaning in life and quality of life of late adolescents with tenninal cancer. Journal of Korean Academy of Nursing, 39(6), 759-768.

Kezar, A., Chambers, A. C., \& Burkhardt, J. C. (Eds.). (2015). Higher education for the public good: Emerging voices from a national movement. John.

Kleiman, E. M., \& Beaver, J. K. (2013). A meaningful life is worth living: Meaning in life as a suicide resiliency factor. Psychiatry Research, 210(3), 934-939.

Lawford, H. L., \& Ramey, H. L. (2015). "Now I know I can make a difference": Generativity and activity engagement as predictors of meaning making in adolescents and emerging adults. Developmental Psychology, 51(10), 1395-1406.

Machell, K. A., Disabato, D. J., \& Kashdan, T. B. (2016). Buffering the negative impact of poverty on youth: The power of purpose in life. Social Indicators Research, $126(2), 845-861$. 
Martela, F., \& Steger, M. F. (2016). The three meanings of meaning in life: Distinguishing coherence, purpose, and significance. The Journal of Positive Psychology, 11(5), 531-545.

Martin Sanz, N., Rodrigo, I. G., Garcia, C. I., \& Pastrana, P. A. (2017). Exploring Academic Performance: Looking beyond Numerical Grades. Universal Journal of Educational Research, 5(7), 1105-1112.

Masten, A. S., \& Reed, M. G. J. (2002). Resilience in development. Handbook of positive psychology, 74-88.

McAdams, D. P., \& McLean, K. C. (2013). Narrative identity. Current Directions in Psychological Science, 22(3), 233-238.

Niemiec, C. P., \& Ryan, R. M. (2009). Autonomy, competence, and relatedness in the classroom: Applying self-determination theory to educational practice. Theory and Research in Education, 7(2), 133-144.

Norrish, J. M., \& Seligman, M. E. (2015). Positive education: The Geelong Grammar School journey. Oxford, UK: Oxford Positive Psychology Series.

O’Donnell, M. B., Bentele, C. N., Grossman, H. B., Le, Y., Jang, H., \& Steger, M. F. (2014). You, me, and meaning: An integrative review of connections between relationships and meaning in life. Journal of Psychology in Africa, 24, 69-79.

Olesen, F., \& Madsen, M. O. (2017). Problem-based learning: A non-mainstream way to teach economics. International Journal of Pluralism and Economics Education, 8(3), 300-311.

Park, C. L. (2010). Making sense of the meaning literature: An integrative review of meaning making and its effects on adjustment to stressful life events. Psychological Bulletin, $136(2), 257-301$.

Perin, D. (2011). Facilitating student learning through contextualization: A review of evidence. Community College Review, 39(3), 268-295.

Peterson, C., Park, N., \& Seligman, M. E. (2005). Orientations to happiness and life satisfaction: The full life versus the empty life. Journal of Happiness Studies, $6(1), 25-41$.

Rae, D. (2010). Universities and enterprise education: Responding to the challenges of the new era. Journal of Small Business and Enterprise Development, 17(4), 591606.

Ramirez, R. R. (2017). Teaching ethics through court judgments in Finance, Accounting, Economics and Business. Nordic Journal of Applied Ethics, 1, 61-87.

Ratner, K., Burrow, A. L., Burd, K. A., \& Hill, P. L. (2019). On the conflation of purpose and meaning in life: A qualitative study of high school and college student conceptions. Applied Developmental Science, 1-21.

Reker, G. T., \& Peacock, E. J. (1981). The Life Attitude Profile (LAP): A multidimensional instrument for assessing attitudes toward life. Canadian Journal of Behavioural Science/Revue Canadienne Des Sciences Du Comportement, 13(3), 264-273.

Reker, G. T., \& Wong, P. T. P. (1988). Aging as an individual process: Toward a theory of personal meaning. In J. E. Birren \& V. L. Bengston (Eds.), Emergent theories of aging (pp. 214-246). New York: Springer. 
Reker, G. T., \& Wong, P. T. P. (2012). Personal meaning in life and psychosocial adaptation in the later years. The human quest for meaning: Theories, research, and applications, 433-456.

Roberts-Mahoney, H., Means, A. J., \& Garrison, M. J. (2016). Netflixing human capital development: Personalized learning technology and the corporatization of K-12 education. Journal of Education Policy, 31(4), 405-420.

Ryff, C. D. (1989). Happiness is everything, or is it? Explorations on the meaning of psychological well-being. Journal of Personality and Social Psychology, 57(6), 1069-1081.

Salter, E., \& Stallard, P. (2004). Posttraumatic growth in child survivors of a road traffic accident. Journal of Traumatic Stress, 17(4), 335-340.

Schwartz, S. J., Côté, J. E., \& Arnett, J. J. (2005). Identity and agency in emerging adulthood: Two developmental routes in the individualization process. Youth \& Society, 37(2), 201-229.

Seligman, M. (2011). Fourish: A visionary new understanding of happiness and wellbeing. New York: Free Press.

Shek, D. T. (1992). Meaning in life and psychological well-being: An empirical study using the Chinese version of the Purpose in Life Questionnaire. The Journal of Genetic Psychology, 153(2), 185-200.

Shochet, I. M., Dadds, M. R., Ham, D., \& Montague, R. (2006). School connectedness is an underemphasized parameter in adolescent mental health: Results of a community prediction study. Journal of Clinical Child \& Adolescent Psychology, 35(2), 170-179.

Shoshani, A., \& Russo-Netzer, P. (2017). Exploring and assessing meaning in life in elementary school children: Development and validation of the meaning in life in children questionnaire (MIL-CQ). Personality and Individual Differences, 104, 460-465.

Shoshani, A., \& Slone, M. (2017). Positive education for young children: Effects of a positive psychology intervention for preschool children on subjective well being and learning behaviors. Frontiers in Psychology, 8, 1866.

Shoshani, A., \& Steinmetz, S. (2014). Positive psychology at school: A school-based intervention to promote adolescents' mental health and well-being. Journal of Happiness Studies, 15(6), 1289-1311.

Shoshani, A., Steinmetz, S., \& Kanat-Maymon, Y. (2016). Effects of the Maytiv positive psychology school program on early adolescents' well-being, engagement, and achievement. Journal of School Psychology, 57, 73-92.

Steger, M. F. (2012a). Making meaning in life. Psychological Inquiry, 23(4), 381385.

Steger, M. F. (2012b). Experiencing meaning in life: Optimal functioning at the nexus of spirituality, psychopathology, and well-being. In P. T. P. Wong (Ed.), The human quest for meaning (2nd ed., pp. 165-184). New York: Routledge.

Steger, M. F., Fitch-Martin, A. R., Donnelly, J., \& Rickard, K. M. (2015). Meaning in life and health: Proactive health orientation links meaning in life to health 
variables among American undergraduates. Journal of Happiness Studies, 16(3), 583-597.

Steger, M. F., Frazier, P., Oishi, S., \& Kaler, M. (2006). The Meaning in Life Questionnaire: Assessing the presence of and search for meaning in life. Journal of Counseling Psychology, 53, 80-93.

Steger, M. F., Frazier, P. A., \& Zacchanini, J. L. (2008). Terrorism in two cultures: Stress and growth following September 11 and the Madrid train bombings. Journal of Loss and Trauma, 13(6), 511-527.

Steger, M. F., Shim, Y., Rush, B. R., Brueske, L. A., Shin, J. Y., \& Merriman, L. A. (2013). The mind's eye: A photographic method for understanding meaning in people's lives. The Journal of Positive Psychology, 8(6), 530-542.

Symonds, W. C., Schwartz, R., \& Ferguson, R. F. (2011). Pathways to prosperity: Meeting the challenge of preparing young Americans for the 21st century. Cambridge, MA: Pathways to Prosperity Project, Harvard University Graduate School of Education.

Tan, L., Chen, J., Xia, T., \& Hu, J. (2018). Predictors of suicidal ideation among children and adolescents: roles of mental health status and meaning in life. In Child \& Youth Care Forum (Vol. 47, No. 2, pp. 219-231). Springer US.

Waters, L. (2011). A review of school-based positive psychology interventions. The Educational and Developmental Psychologist, 28(2), 75-90.

Weathers, L. N., Aiena, B. J., Blackwell, M. A., \& Schulenberg, S. E. (2016). The significance of meaning to conceptualizations of resilience and posttraumatic growth: Strengthening the foundation for research and practice. In Clinical perspectives on meaning (pp. 149-169). Cham: Springer.

Williams, P. (2011). Pathways to positive education at Geelong Grammar School. Integrating positive psychology and appreciative inquiry. AI Practitioner, 13(2), 813.

Yuen, M., \& Yau, J. (2015). Relation of career adaptability to meaning in life and connectedness among adolescents in Hong Kong. Journal of Vocational Behavior, 91, 147-156. 
Open Access This chapter is licensed under the terms of the Creative Commons Attribution 4.0 International License (http://creativecommons.org/licenses/by/4.0/), which permits use, sharing, adaptation, distribution and reproduction in any medium or format, as long as you give appropriate credit to the original author(s) and the source, provide a link to the Creative Commons license and indicate if changes were made.

The images or other third party material in this chapter are included in the chapter's Creative Commons license, unless indicated otherwise in a credit line to the material. If material is not included in the chapter's Creative Commons license and your intended use is not permitted by statutory regulation or exceeds the permitted use, you will need to obtain permission directly from the copyright holder.

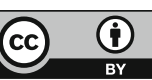

